SEÇÃO TEMÁTICA:

CAPITALISMO, ESTADO E EDUCAÇÃO:

OS LIMITES DO CAPITAL

\title{
Educação e Inclusão: equidade e aprendizagem como estratégias do capital
}

\author{
Rosalba Maria Cardoso Garcia' \\ Maria Helena Michels'
}

'Universidade Federal de Santa Catarina (UFSC), Florianópolis/SC - Brasil

RESUMO - Educação e Inclusão: equidade e aprendizagem como estratégias do capital. Discutimos orientações internacionais de políticas educacionais entre 1990 e 2020 e analisamos três gerações de políticas de educação especial no Brasil, relacionando o eixo educação e inclusão e as estratégias equidade e aprendizagem. As estratégias têm relação com diversificação educacional, flexibilização curricular, diferenciação de trajetórias, habilidades e competências que prescindem das instituições escolares e do conhecimento. Identificamos uma perspectiva multifacetada relacionada à inclusão, combinando atendimentos segregados e integracionistas. As proposições em tela induzem ao rebaixamento formativo e processos de desescolarização, reforçando os mecanismos de desigualdade constitutivos da sociabilidade do capital.

Palavras-chave: Educação. Inclusão. Equidade. Aprendizagem. Organismos Internacionais.

ABSTRACT - Education and Inclusion: equity and learning as capital strategies. In this article, international educational policy guidelines between 1990 and 2020 were discussed, and three generations of special education policies in Brazil were analyzed, relating education and inclusion with equity and learning strategies. Such strategies are related to educational diversification, curriculum flexibility, differentiation of trajectories, and skills and competencies that do not require school institutions and knowledge. There is a multifaceted perspective related to inclusion, combining segregated and integrationist services. The proposals under discussion lead to lower education levels and de-schooling processes, reinforcing the inequality mechanisms that constitute capital sociability.

Keywords: Education. Inclusion. Equity. Learning. International Organizations.

Educação \& Realidade, Porto Alegre, v. 46, n. 3, e116974, 2021. 


\section{Introdução ao Debate: organismos internacionais e o eixo educação e inclusão}

Os organismos internacionais têm atuado de forma decisiva com orientações às políticas educacionais nos países periféricos com vistas a delinear tendências para a formação dos trabalhadores, expandir a produção e consumo de tecnologias e formular consensos nos direcionamentos políticos nas áreas econômica e social.

Na década de 1990, as ideologias da globalização, da sociedade do conhecimento, e o desenvolvimento de políticas de matiz neoliberal em países periféricos endividados contribuíram para colocar em curso um conjunto de reformas com delineamentos na área da educação. Segundo Leher (1999, p. 25), é a “[...] conexão entre conhecimento e ordem que constitui o 'núcleo sólido' das proposições do Banco Mundial para a educação na década de 1990". Para o autor, se por um lado a ordem tem relação com as questões de segurança e controle das insurgências políticas, por outro, o conhecimento não é referido em relação a sua apropriação pelos sujeitos com vistas ao desenvolvimento humano. Trata-se de uma perspectiva renovada da teoria do capital humano na qual o mercado define os conhecimentos úteis ao seu desenvolvimento e que devem ser mobilizados para o processo produtivo. A educação, portanto, ganha centralidade nos discursos dos organismos internacionais como o Banco Mundial, além da UNESCO, que já assumia o papel de orientar as políticas setoriais nos países periféricos.

A partir dos anos 1990, tais orientações relacionam o desenvolvimento à educação orientada pelo e para o mercado. Em consonância a essa análise, Evangelista e Shiroma $(2004$, p. 1) sistematizam alguns dos conceitos que acompanham os discursos políticos dos organismos internacionais no início dos anos 1990: "[...] produtividade, qualidade, competitividade, eficiência e eficácia”.

Já no final da década de 1990, os discursos dos organismos internacionais forjam uma face humanitária em lugar do economicismo, depositando na educação a solução das mazelas sociais. Os conceitos destacados por Evangelista e Shiroma (2004, p. 2) nesse período são: “[...] justiça, equidade, coesão social, inclusão, empowerment, oportunidade e segurança”.

Se, na década de 1990, o slogan divulgado era educação para competitividade, na virada do século XXI, localizamos o lema educação para o combate à pobreza. Por certo, não um combate às raízes dos processos sociais contraditórios geradores de pobreza e desigualdade, já que são formas instituídas pelo Estado burguês para administrar os riscos sociais da pobreza e a canalização de investimentos sociais em torno de públicos-alvo. Os grupos específicos em questão seriam atendidos mediante políticas focais com a participação de organizações privadas, de caráter empresarial e associações relacionadas à filantropia.

A atuação do Estado burguês (Marx, 2012) para conter a pobreza mediante políticas focalizadas busca deslocar a atenção dos efeitos 
da crise estrutural do capital, sintetizada por Antunes (2000) em seis dimensões: a queda da taxa de lucro pela redução dos níveis de produtividade; o esgotamento do padrão de acumulação taylorista/fordista de produção, acompanhada pelo desemprego estrutural; hipertrofia da esfera financeira; crise do Estado de bem estar social, com transferência de recursos públicos para o capital privado; tendência generalizada de privatizações e desregulamentações.

Tal movimento de reorganização e reposição do capital pode ser observado mediante o desemprego, a expansão do trabalho informal, índices elevados de pessoas sem renda, sem teto, sem terra, com um aprofundamento da violência urbana e rural. O novo modelo de acumulação reorganiza o trabalho em nível internacional, redefinindo assim as desigualdades entre e intra os países no que se refere à produção e ao consumo, à exploração e à expropriação com a retirada dos direitos sociais.

Contraditoriamente, numa conjuntura de ataques aos direitos e transformações no mundo do trabalho, o conceito inclusão, apresentado como em oposição à exclusão, emerge nos discursos políticos dos organismos internacionais articulado à educação (UNESCO, 1994; Dahrendorf, 1995; UNESCO, 1999a; UNESCO, 1999b; Banco Mundial, 2000; Holzmann; Jorgensen, 2000; Banco Mundial, s/d). Compreendemos sua divulgação como pilar de políticas educacionais de caráter neoliberal articuladas à reestruturação produtiva e às contradições acirradas pela reorganização do capital, motivadas pelo novo padrão de acumulação flexível, em resposta à recomposição das taxas de lucro, na sua face articulada à exploração, assim como aos processos de formulação de políticas na área social e educacional, com restrição dos fundos públicos para a educação pública e ampliação do mercado educacional, na sua face articulada à expropriação.

O termo inclusão, na educação, foi apreendido como parte de discursos progressistas de viés pós-moderno, ou sem referência na objetividade da sociedade de classes, como afirmação de direitos, de reconhecimento de identidades e de respeito a diferenças. Entretanto, ao perseguir uma análise dialética do real, não passa despercebida sua filiação conservadora na produção discursiva pela manutenção, exaltação e adaptação dos sujeitos à ordem social. Nessa direção de pensamento, podemos formular como hipótese que o conceito inclusão é mobilizado reiteradamente pela burguesia internacional no intuito de restabelecer a confiança na sociabilidade do capital, quer seja por sua conexão com as ideias de coesão e sustentabilidade social, quer seja por sua articulação com áreas específicas de atuação dos Estados nacionais, como é o caso da educação.

O conceito inclusão, contemporâneo aos movimentos de mundialização do capital (Chesnais, 2001), teve destaque no debate das políticas sociais a partir de meados dos anos 1990, com ênfase própria na área da educação e, particularmente, na educação especial. Justamente em face ao aprofundamento da produção mundial de desigualdade social, esse conceito ganha a cena como recomendação de organismos 
Educação e Inclusão

internacionais para governos de diferentes países, assumindo uma característica multifacetada de suas proposições. Na prática, a recomendação comum de inclusão na educação foi incorporada como políticas diferentes em diferentes formações sociais pelo mundo.

Contudo, ainda que o conceito inclusão tenha sido apropriado nos discursos políticos internacionais nos anos 1990, já estava presente nas décadas de 1960 e 1970 na análise sociológica. Parsons (1966), assumindo a compreensão funcionalista, discute o conceito inclusão compreendendo que o termo retrata uma das etapas da estrutura do sistema social, constituindo-se na diferenciação de grupos sociais até então não percebidos como parte da sociedade. Nessa análise, Parsons (1966) relaciona inclusão à necessidade de promover a capacidade adaptativa, ou adaptação social. Afirma, portanto, a difusão para toda a sociedade de valores comuns e determinados como favoráveis ao seu bom desenvolvimento, ressaltando que antes da adaptação social existem estágios do desenvolvimento da estrutura social como a seleção e a diferenciação. Podemos sintetizar, desse modo, que as políticas públicas para a educação são formuladas mediante uma apropriação liberal do conceito inclusão e corroboram para a defesa da manutenção do status quo e consequente naturalização das desigualdades sociais.

A percepção das políticas de inclusão como constitutivas de conjunto de proposições e iniciativas de caráter conservador da ordem social e de suas raízes em uma matriz de pensamento que explica de maneira mecânica como as relações sociais contribuem para questionarmos a aura de inovação e revolução nas proposições políticas educacionais, tendo sido até mesmo tratada como novo paradigma social. Ademais, no processo de divulgação do conceito como pilar das políticas educacionais, ganhou também uma conotação multicultural.

Por um lado, Habermas (1998) avalizou os processos de inclusão nas sociedades multiculturais com base na democracia, no Estado de direito, na soberania popular, afirmando que as minorias devem ser integradas e ter suas necessidades equalizadas, sem, contudo, serem incorporadas de forma homogênea. Em sua concepção, inclusão significa que uma ordem política se mantém aberta para a equalização dos discriminados e para a integração dos marginalizados, sem incorporá-los na uniformidade de uma comunidade popular homogeneizada (Habermas, 1998, p. 108). Por outro lado, Touraine (1991 apud Oliveira, 2000) afirma que, na organização social contemporânea, a compreensão de classes sociais estaria superada por uma organização na relação centro/ periferia, tanto para os Estados nacionais quanto para os indivíduos.

Tais autores desenvolvem suas perspectivas mediante o abandono da existência de classes sociais e de suas relações de desigualdade, negligenciando a apreensão da realidade social. Nessa direção, privilegiam uma abordagem das diferenças que não leva em conta a luta de classes, presença constante no metabolismo social do capital. A ênfase em diferenças tratadas como supostamente horizontais, baseadas em grupos que se diferenciam de modo essencialista, favorece uma apreensão acrítica da ideia de inclusão no campo das vontades, do volunta- 
rismo, da política abstraída dos movimentos de exploração e expropriação que constituem as relações sociais capitalistas contemporâneas.

Localizamos, ainda, autores que assumem que a sociedade de classes deve ter uma dimensão equitativa, reenquadrando o debate da desigualdade social com base nessa categoria. Dentre eles, destacamos Phillips e Berman (2001), que discutiram na virada do século a inclusão social compreendida como relacionada aos princípios de igualdade e equidade. Segundo esses autores, num contexto de qualidade social, o objetivo é um nível básico de inclusão com auxílio de infraestrutura de suporte, condições de trabalho e bens coletivos, prevenindo e minimizando os mecanismos que causam exclusão social. Neste caso, políticas de inclusão poderiam evitar ou reduzir a ocorrência de situações de exclusão social, mas não atacam a questão da desigualdade social.

Já Popkewetz e Lindblad (2001), no mesmo período, denunciavam a insuficiência das medidas para conter a exclusão ou ampliar a inclusão ao enquadrar os sujeitos em padrões de normalidade e desvio. Uma vez que as políticas de inclusão não atuam sobre as causas da exclusão, agindo na esfera de uma sociabilidade excludente, produzem, em alguns casos, apenas mecanismos de contenção dos excessos. Segundo os autores, os estudos realizados pelo Estado para definir quem necessita de intervenção das políticas públicas abordam a realidade social como um campo inteligível e calculável, de modo a planejar suas ações, indicando a matriz gerencialista na gestão do Estado no início do século XXI. Na prática, essa matriz é geradora de políticas sociais focalizadas em grupos identificados como excluídos ou vulneráveis, que podem variar de país para país e que, ao contrário do que anunciam, se afastam de uma proposta de reconhecimento de direitos na medida em que não se pretende universalizá-los.

Podemos afirmar, portanto, que as políticas de inclusão são marcadas pela luta de classes, pela ação do Estado capitalista na sua implementação em favor dos interesses do mercado. Nessa direção, Fontes (1996) confronta o pensamento liberal ao afirmar que, mediante as relações de exploração e expropriação, estamos em situação de inclusão forçada na sociabilidade do capital. A autora se apóia nas reflexões de Balibar para quem "[...] ninguém pode ser excluído do mercado, simplesmente porque ninguém pode dele sair, posto que o mercado é uma forma ou uma 'formação social' que não comporta exterioridade" (Balibar apud Fontes, 1996, p. 5). Portanto, as políticas de inclusão justificam formas de controle, dominação de classe e estratégias de minimização dos gastos públicos com as frações mais fragilizadas da classe trabalhadora.

Shiroma (2001) reforça essa análise ao explorar a contribuição de Levitas que percebe mudanças na abordagem sobre inclusão em face das mudanças no mundo do trabalho. Levitas (apud Shiroma, 2001) discute três tipos de discursos sobre inclusão/exclusão: o redistribucionista, o integracionista e o de subclasse. O discurso redistribucionista estaria identificado com uma preocupação com a pobreza e sua redução pela distribuição de riqueza e poder; o integracionista teria como foco 
o desemprego e, nesse caso, a inclusão significaria treinamento profissional e inserção no mercado de trabalho; já o discurso da subclasse trabalharia com noções de moral, valores, hábitos culturais. O conteúdo discursivo aqui explanado poderia interpelar os trabalhadores no sentido da reposição das relações de hegemonia, ao difundir ideias de coesão social.

Ao longo das últimas décadas, o discurso dos organismos internacionais tem orientado as ações dos Estados nacionais mediante propostas sobre inclusão em sentido amplo. A inclusão escolar, ou a educação inclusiva, tem se convertido em slogans das políticas educacionais nos últimos anos, fazendo-se presente nos discursos políticos internacionais mediante documentos do Banco Mundial (BM) e da Organização das Nações Unidas para a Educação, a Ciência e a Cultura (UNESCO).

Mais recentemente, identificamos que o sentido de coesão presente nos discursos políticos toma a forma de sustentabilidade, conforme registrado nos objetivos do desenvolvimento sustentável (UNESCO, 2015) e nas proposições do Banco Mundial (Banco Mundial, 2011). O objetivo 4 do desenvolvimento sustentável foi proposto à área da educação com as palavras-chave inclusiva, equitativa e ao longo da vida. Se no final do século XX o slogan orientador indicava Educação para todos, agora, o Banco Mundial (2011) reitera a "[...] expansão e melhoria da educação" como estratégia de adaptação às mudanças e apresenta o novo lema aprendizagem para todos. A teoria do capital humano serve de baliza a essa estratégia, com a priorização da economia em relação ao desenvolvimento humano, observada pela articulação direta da aprendizagem ao desenvolvimento econômico e à redução da pobreza, de forma autônoma em relação aos processos educacionais e de ensino. Para Pronko (2014, p. 106)

[...] ao longo das últimas décadas, houve uma grande evolução, sobretudo nos países em desenvolvimento, nas matrículas, na retenção escolar e na igualdade de gênero na escola, fruto da operacionalização da diretriz 'Educação para Todos', definida na Conferência de Jomtiem em 1990, e dos esforços nacionais para alcançar os Objetivos do Milênio. Entretanto, segundo o documento, esses avanços, embora importantes, não são suficientes em face dos desafios contemporâneos e requerem do banco e dos seus parceiros para o desenvolvimento uma nova estratégia de educação para a próxima década. Nesse contexto, a educação, como ferramenta central para o desenvolvimento, deve ser considerada não mais exclusivamente na perspectiva da escolarização, mas, sobretudo e de forma estratégica, da aprendizagem.

A UNESCO é o organismo que reforça mais explicitamente a noção de desenvolvimento sustentável mediante os propósitos da Agenda 2030 (UNESCO, 2015). No bojo desse discurso, os termos inclusão e equidade são tratados como princípios abrangentes que norteiam todas as políticas, os planos e as práticas educacionais (UNESCO, 2019), inserindo mudanças em relação às aprendizagens. 


\section{Um Novo Ciclo de Recomendações Mediante a Governança Global: educação e inclusão com base nas estratégias equidade e aprendizagem}

No início do século XXI, observamos a ação coordenada dos organismos internacionais atuando com efeito de governança global (Robertson; Verger, 2012). Após os movimentos de educação para todos (UNESCO, 1990), cujos princípios foram reafirmados no encontro de Dakar (UNESCO, 2000), desdobraram-se palavras de ordem tais como a satisfação das necessidades básicas de aprendizagem articulada aos pilares aprender a aprender, aprender a ser, aprender a fazer e aprender a conviver, e os slogans de desenvolvimento sustentável e educação para a paz.

A discussão em torno desse compromisso definiu novas metas e um novo prazo para seu cumprimento, tomando como data referência o ano de 2015. Os países signatários ficaram instados a desenvolver ações pela qualidade da educação, gerando resultados de aprendizagem satisfatórios, reconhecidos e mensuráveis, a serem verificados mediante avaliações externas. Ainda que o discurso político reitere a noção de direito à educação pela defesa do acesso e da qualidade educacional, a noção de equidade direciona para medidas focalizadas, ações que visem à incorporação pelos sistemas de ensino de grupos considerados vulneráveis. Por outro lado, o foco nos resultados de aprendizagem não coaduna com ações de fortalecimento das condições de produção do trabalho de professores e de estudo, mas um investimento em avaliações que produzam dados que possam ser acompanhados e comparados.

Uma nova conferência foi realizada ao final do período proposto, o Fórum Mundial de Educação em Incheon, na Coréia do Sul (2015). Decorre desse Fórum, em meio a um conjunto de outros debates, a publicação da Declaração de Incheon, que propõe tratar as questões inacabadas da agenda da Educação para Todos (EPT) e os Objetivos do Desenvolvimento do Milênio (ODM) relacionados à educação (UNESCO, 2015). E para tanto, os Estados nacionais são definidos como provedores do direito à educação, devendo assegurar a educação inclusiva e equitativa de qualidade, e promover oportunidades de aprendizagem ao longo da vida para todos, conforme descrito no objetivo do desenvolvimento sustentável 4 - ODS4. A importância da relação educação/aprendizagem/equidade/inclusão está retratada nessa declaração (UNESCO, 2015, p. 7):

$$
\begin{aligned}
& \text { Reconhecemos a educação como elemento-chave para } \\
& \text { atingirmos o pleno emprego e a erradicação da pobreza. } \\
& \text { Concentraremos nossos esforços no acesso, na equidade } \\
& \text { e na inclusão, bem como na qualidade e nos resultados da } \\
& \text { aprendizagem, no contexto de uma abordagem de educa- } \\
& \text { ção ao longo da vida. }
\end{aligned}
$$

A exemplo da política educacional implementada nos EUA por George W. Bush em 2002, No Child Left Behind (NCLB), o discurso político inclusivo anuncia que ninguém deve ser deixado para trás, slogan 
que pode ser apreendido como um princípio universalista. Entretanto, tal ideia não se sustenta ao ser confrontada com estratégias voltadas aos mais vulneráveis, o que permite perceber claramente a caracterização de uma proposta focalizada, bem aos modos das políticas neoliberais.

Percebemos nesse novo ciclo das políticas orientadas por organismos internacionais duas estratégias que se articulam ao eixo educação e inclusão: a equidade e a aprendizagem.

\section{A Estratégia da Equidade na Relação Educação e Inclusão}

Retomando o discurso político da década de 1990 - educação como eixo da produtividade com equidade - observamos, naquele período, a defesa do acesso à educação e de um padrão mínimo de qualidade de aprendizagem. Compreendemos que tal discurso ganhava força de inovação para suplantar a bandeira política em defesa da igualdade. A equidade foi relacionada no discurso político à justiça social, de modo que, sob essa regência, as desigualdades reais se tornaram, no bojo das políticas internacionais, mais aceitáveis, uma vez que os processos de focalização contêm elementos de respeito às diferenças e reconhecimento da diversidade. Nessa direção, os discursos de inclusão e equidade foram articulados às recomendações de organismos internacionais para pensar a educação como importante instrumento político para a redução da pobreza, por meio de medidas focalizadas. Junto a essa defesa, temos uma redefinição do papel do Estado burguês como centralizador e mediador das estratégias público/privadas na generalização de uma lógica empresarial na educação, assim explicada por Freitas (2014, p. 1088):

[...] procura-se difundir que a questão da educação se resolve a partir de uma gestão eficaz das mesmas formas vigentes de organização pedagógica, associada a novas tecnologias educativas, responsabilização, meritocracia e privatização, motivando a consolidação de um neotecnicismo educacional (Freitas, 2011), em um grande movimento para adaptar as escolas às novas exigências da reestruturação produtiva e da promoção do aumento da produtividade empresarial [...].

A questão da equidade joga luz não somente sobre a substituição de um parâmetro de igualdade, mas favorece o desenvolvimento do pensamento liberal na educação, de seus princípios, na formulação de um consenso na educação segundo o qual o que importa são os resultados de aprendizagem e não os processos de estudo e de ensino e o próprio desenvolvimento humano. Conforme (Freitas, 2014, p. 1090), "Os liberais não convivem com a igualdade de resultados, apenas com a igualdade de oportunidade”. Desse modo, observa-se uma disputa pelo controle da oferta da educação e uma disputa do projeto educacional da oferta de aprendizagens que expõem os limites de se pensar na atual conjuntura mundial sobre educação e aprendizagem como direitos. Para Freitas (2014, p. 101), 
Equidade diz respeito à igualdade, mas não é a igualdade em si mesma. É a garantia de acesso a um direito que deve ser para todos, mediado pela justiça social. Para os novos reformadores, a exigência de igualdade plena no processo educacional seria 'totalitária', no sentido de que violentaria as particularidades do sujeito.

Na relação educação e inclusão, a estratégia da equidade contempla um nível de igualdade de oportunidades, mas como os sujeitos humanos vão lidar com tais oportunidades em regime de desigualdade social e educacional, numa conjuntura de ampliação das formas de exploração e de expropriações é uma questão do campo da responsabilidade individual, bem ao estilo do pensamento liberal.

Na Declaração de Incheon (UNESCO, 2015, p. 7), localizamos a articulação da equidade de forma mais direta ao eixo educação e inclusão, demonstrando um aprofundamento da atuação focalizada nos mais desfavorecidos, reforçando que as transformações devem ocorrer na esfera educacional e não em relação às relações sociais vigentes.

\begin{abstract}
Inclusão e equidade na e por meio da educação são o alicerce de uma agenda de educação transformadora e, assim, comprometemo-nos a enfrentar todas as formas de exclusão e marginalização, bem como disparidades e desigualdades no acesso, na participação e nos resultados de aprendizagem. Nenhuma meta de educação deverá ser considerada cumprida a menos que tenha sido atingida por todos. Portanto, comprometemo-nos a fazer mudanças necessárias nas políticas de educação e a concentrar nossos esforços nos mais desfavorecidos, especialmente aqueles com deficiências, a fim de assegurar que ninguém seja deixado para trás (UNESCO, 2015, p. 7).
\end{abstract}

A estratégia da equidade, portanto, articulada ao eixo educação e inclusão reafirma as desigualdades sociais como próprias da sociabilidade do capital, naturalizando suas causas e efeitos e reforçando um ciclo vicioso de reformas educacionais funcionais ao sistema social.

\title{
A Estratégia da Aprendizagem na Relação Educação e Inclusão
}

No início dos anos de 1990, a CEPAL/UNESCO (1990) já afirmava que para a transformação produtiva pressupunha-se a existência de recursos humanos capazes de adaptarem-se a mudanças necessárias ao setor, e que a educação seria condição para que a "[...] economia avance por um caminho de crescimento sustentável e equânime” (CEPAL/UNESCO, 1990, p. 121). Atrelando a transformação produtiva com o avanço da tecnologia, os organismos internacionais difundiam a idéia de um tipo de conhecimento, combinado com habilidades, que a educação deveria se ocupar para atender a demanda de trabalhadores adaptáveis ao mercado (novo trabalhador). Essa articulação conhecimentos/habilidades foi denominada necessidades básicas de aprendiza- 
gem. Mello (1994) utiliza o conceito de Necessidades Básicas de Aprendizagem apresentadas pela Conferência Mundial de Educação para Todos, realizada em Jomtien - Tailândia (1990) e afirma que estas:

\begin{abstract}
[...] compreendem tanto os instrumentos fundamentais da aprendizagem (a alfabetização, a expressão oral, a aritmética e a solução de problemas) quanto o conteúdo básico da aprendizagem (conhecimento, capacidades, valores e atitudes) de que necessitam os seres humanos para sobreviver, desenvolver plenamente suas possibilidades, viver e trabalhar dignamente, participar plenamente do desenvolvimento, melhorar sua qualidade de vida, tomar decisões fundamentadas e continuar aprendendo (Mello, 1994, p. 35).
\end{abstract}

A autora afirma que este novo perfil está associado à inteligência, conhecimento, capacidade de resolver problemas, liderança e adaptação a novas situações. Desta maneira, o indivíduo tem que ter conhecimento/habilidade para atender as necessidades do capital.

Na Conferência Mundial de Educação para Todos (1990), os países membro assumem o compromisso de contemplar os excluídos em sua proposta educacional, com a retórica da educação para todos. Centrado nas necessidades básicas de aprendizagem (NEBA), que não são as mesmas para todos, a educação também é proposta de maneira diferenciada.

Durante a primeira década dos anos 2000, o discurso ainda se assentava sobre o slogan Educação para todos, porém, na segunda década, passa a advogar que o objetivo para o desenvolvimento em nível global não é somente escolaridade, mas também aprendizagem.

\begin{abstract}
O motor deste desenvolvimento no entanto será, em última análise, o que as pessoas aprendem, dentro e fora da escola, desde o jardim-escola até ao mercado de trabalho. A nova estratégia do Banco para 10 anos procura alcançar este objetivo alargado de 'Aprendizagem para Todos', promovendo reformas nos sistemas de educação dos países e criando uma base global de conhecimento suficientemente forte para liderar estas reformas (Banco Mundial, 2011, p. 1).
\end{abstract}

Para este organismo internacional, o crescimento econômico e a redução da pobreza dependem dos conhecimentos adquiridos pelas pessoas. Porém, nesse mesmo documento do Banco Mundial (2011), observa-se que esse conhecimento pode ser adquirido dentro ou fora da escola. Como indica Pronko (2014, p. 108), há um alargamento da compreensão de educação, não mais baseada na instituição escolar, mas nas (difusas) oportunidades de aprendizagem.

Para o Banco Mundial (2011, p. 4),

O ponto essencial da estratégia para a educação do Grupo do Banco é: investir cedo. Investir com inteligência. Investir em todos. Em primeiro lugar, as competências fun- 
damentais adquiridas na infância tornam possível uma vida inteira de aprendizagem [...]. Segundo, para obter o melhor valor por cada dólar aplicado na educação, é preciso fazer investimentos hábeis - aqueles que já provaram contribuir para a aprendizagem. A qualidade tem de ser o fulcro dos investimentos na educação, com os ganhos de aprendizagem como medida-chave da qualidade. Terceiro, aprendizagem para todos significa garantir que todos os estudantes e não só os mais privilegiados ou talentosos possam adquirir o saber e as competências de que necessitam. Este objectivo exige que se removam as barreiras que mantêm as raparigas, pessoas portadoras de deficiências e minorias etnolinguísticas, fora do quadro educacional acessível a outros grupos da população.

Desta maneira, a aprendizagem é assumida como ponto estratégico que deve ser alcançado a partir das oportunidades de aprendizagem. E é nesse quesito que se deve investir na educação, que, como indica Pronko (2014), favorece os mercados de formação que promovem a disseminação das competências e das capacidades individuais necessárias para o desenvolvimento. Embora nessa estratégia a escola perca centralidade no processo educacional, como ainda não será possível prescindir dela, torna-se necessário adequá-la também a esses novos requerimentos.

Reforçando a ideia de que a aprendizagem não ocorre necessariamente na escola, o Banco Mundial, em seu documento Aprendizagem para Todos: investir nos conhecimentos e competências das pessoas para promover o desenvolvimento (Banco Mundial, 2011), reitera a compreensão de que a inclusão melhora a aprendizagem de todos os alunos.

Observamos no discurso político uma mudança do slogan Educação para todos, da década de 1990, para o lema Aprendizagem para todos, presente nos documentos do BM (2011) e na Declaração Incheon (UNESCO, 2015). Esse último, em sua agenda 2030, coloca no centro do debate o Desenvolvimento Sustentável como Objetivo do Desenvolvimento do Milênio (UNESCO, 2015). A agenda 2030 indica que para o Desenvolvimento Sustentável deve-se "Assegurar a educação inclusiva e equitativa de qualidade, e promover oportunidades de aprendizagem ao longo da vida para todos" (UNESCO, 2015, p. 22).

Para realizar a promessa da educação, a UNESCO indica que a aprendizagem é fundamental (UNESCO, 2019). Nesse documento, sugere que há uma crise da aprendizagem, apresentada em três dimensões: os resultados da aprendizagem; de causas imediatas e de causas sistêmicas mais profundas. Nesse caso, fica evidente que a aprendizagem diz respeitos às “[...] habilidades adquiridas por meio da educação e não apenas o tempo despendido na escola que conduzem o crescimento e proporcionam aos indivíduos os recursos para o trabalho e para a vida” (Banco Mundial, 2018, p. 4). Nessa direção, a aprendizagem como estratégia relacionada ao eixo educação e inclusão sugere que a formação da força de trabalho prescinde das instituições escolares tal como conhecemos e do conhecimento nela difundido. 


\section{Educação e Inclusão e as Disputas Sobre as Políticas de Educação Especial no Brasil}

Na presente seção, vamos estabelecer algumas articulações do eixo educação e inclusão como conteúdo das orientações dos organismos internacionais com as políticas de educação especial na perspectiva da educação inclusiva no Brasil. Para desenvolver esse tópico em suas dimensões estruturais e conjunturais, e levando em conta o regime de conservadorismo político no Brasil, buscamos respaldo nas contribuições de Florestan Fernandes, tanto por sua trajetória política quanto por sua densidade teórica. Florestan Fernandes (2019) destaca o caráter político do trabalho de professores numa sociedade com os níveis de desigualdade como é a brasileira. Em suas análises, leva em consideração a tradição cultural elitista no Brasil e a democracia restrita nas relações políticas em nosso país como elementos que podem levar professores a uma ação de mediação na cadeia de dominação política e cultural. Para ele, aos professores no Brasil foi atribuída a tarefa de responsabilizar-se pela ordem social, estabelecendo um patamar civilizatório para poucos, e ao mesmo tempo não podendo exercer um posicionamento crítico, sendo interpelados a uma separação entre o ser político e o ser pedagógico.

Destaca-se da história da educação brasileira que os professores foram responsabilizados por levar a frente elementos do pensamento burguês renovador para a educação no Brasil, com proposições de mudanças educacionais anunciadas como revolucionárias, como as ideias renovadoras de Anísio Teixeira e Fernando de Azevedo, que propunham mudanças para a educação sem uma correspondência no plano econômico e político (Fernandes, 2019). O autor refere-se a mudanças imprescindíveis ao conservadorismo reformista. Em contraposição a isso, advoga que mudança requer luta, uma luta específica, uma luta social entre classes. E que professores precisam pensar no escopo da luta de classes, precisam estar posicionados como trabalhadores e não na mediação acrítica do pensamento da ordem. Nesse sentido, afirma que para atuar na escola é preciso pensar para além da escola. É preciso ter uma consciência política penetrante (Fernandes, 2019, p. 82).

Ao longo do presente artigo procuramos demonstrar que as políticas de inclusão na educação são propostas pelos países centrais, mediante suas estruturas supranacionais de governança, os organismos internacionais como o Banco Mundial e Unesco, entre outros. Também ressaltamos que as políticas de inclusão estão assentadas sobre a premissa de que a sociedade não estaria mais organizada em classes sociais, não existiria mais um antagonismo capital/trabalho, mas com base em pressupostos do pensamento pós-moderno, a sociedade contemporânea estaria organizada pela participação dos grupos e indivíduos na vida social. Localizam-se com base nesse pensamento, desprovido de base material, uma relação antinômica entre aqueles que estão incluídos e aqueles que estão excluídos (Frigotto, 2010). Esse discurso político sem correlação empírica serviu para formular consensos em 
torno da necessidade de dissolver no mundo todo políticas universalistas baseadas no modelo de Estado de bem-estar social, desenvolvido nos países centrais no pós-guerra. Em seu lugar, o Estado burguês articulou políticas de matiz neoliberal que refutam o modelo universalista e apostam na redução dos investimentos públicos para os setores sociais, colocando o foco nos grupos excluídos, entendidos como aqueles sem condições de buscar os serviços sociais (como educação e saúde) no mercado.

Portanto, as políticas de inclusão, embora tenham sido anunciadas na educação como políticas de educação para todos, foram e são destinadas a todos aqueles que não podem buscar educação no mercado, mediante uma redefinição da educação de direito para serviço. $\mathrm{Ou}$ seja, para esses, a educação é um serviço focalizado, para os demais é uma mercadoria. Destacamos, na virada do século XXI, o movimento de políticas que sustentam reformas empresariais na educação (Freitas, 2014), drenando recursos dos fundos públicos para o mercado e remunerando capitais.

Apesar dessa materialidade objetiva, as políticas de inclusão na educação foram apropriadas no Brasil como reconhecimento do direito à educação e disseminação do respeito às diferenças. Contraditoriamente, numa sociedade de classes e num país de capitalismo dependente como é o caso do Brasil (Fernandes, 2008), a educação ganhou uma forma política de dominação social e de disseminação da ideologia hegemônica burguesa na virada do século. Observamos aí a produção de um consenso por um conjunto importante de aparelhos privados de hegemonia, fundações empresariais, organizações não governamentais, dentre as quais a mais importante atuando na educação no Brasil, o Movimento todos pela educação. Observamos também um enfraquecimento da consciência de classe dos professores, muitos dos quais abraçaram a bandeira da educação inclusiva ou inclusão escolar como uma revolução, quando, de fato, se manifesta como uma mudança renovadora burguesa, no sentido da manutenção da ordem social.

Compreendemos que no Brasil as políticas de educação especial estão propostas em três gerações quando pensamos na perspectiva inclusiva. As três proposições políticas, de acordo com sua conveniência, reafirmam as recomendações internacionais em relação ao tema.

A primeira geração de políticas inclusivas para a educação especial no Brasil está retratada nas Diretrizes Nacionais para a Educação Especial na Educação Básica (Brasil, 2001), no governo Fernando Henrique Cardoso (1996 - 2002). Isso acontece já no segundo mandato presidencial, quando o desenvolvimento de políticas neoliberais já havia articulado uma reforma do aparelho do Estado (Bresser Pereira, 1996), que redefiniu educação como serviço, e levado a cabo um conjunto importante de privatizações de empresas estatais.

Na educação especial, o discurso da inclusão foi ajustado com flexibilizações curriculares que tinham correlação com uma lógica de diferentes serviços que poderiam ser ofertados pelas redes de ensino. 
Estava dada uma indicação de inclusão escolar para os estudantes da educação especial, mas não uma política de indução à matrícula na classe comum, numa convivência de diferentes serviços para diferentes condições humanas, contemplando as organizações privadas e assistenciais (privatização) e sem ampliação de investimentos nas redes de ensino.

A segunda geração de políticas de educação especial na perspectiva inclusiva está relacionada aos governos Lula/Dilma (2003 - 2016) e foi veiculada como política de educação especial na perspectiva inclusiva (Brasil, 2008). Por vezes é identificada como $a$ política inclusiva na educação especial no Brasil. A partir de 2007, um conjunto de programas educacionais de atendimento aos estudantes e de formação docente foi colocado em movimento em relação à educação especial em nível nacional. Tais programas federais estavam articulados a um conjunto mais amplo na área da educação aglutinados ao Plano de Desenvolvimento da Educação - PDE com atuação decisiva do aparelho privado de hegemonia, Movimento Todos pela Educação. Observamos aí a presença do empresariado na formulação de políticas para a educação pública por meio da participação de fundações empresariais e organizações sociais, o que significa um tipo de privatização da educação.

A política de educação especial constituiu o pacote do PDE e alcançou razoável consenso no país, aglutinada pela perspectiva inclusiva compreendida como o acesso, a permanência e a participação dos estudantes vinculados à educação especial nas classes comuns na Educação Básica e Superior, o Atendimento Educacional Especializado - AEE, como complementar ou suplementar ao ensino na Educação Básica, a instituição de um equipamento público próprio para essa finalidade - as sala de recursos multifuncionais, um programa nacional de formação de professores para atuar no AEE, desenvolvido majoritariamente a distância, o estabelecimento de um corpo de professores de educação especial efetivos ou temporários nas redes públicas.

O foco da Política de educação especial no período 2003-2016 é a questão da acessibilidade mediante o serviço do AEE (Brasil, 2009), mas não observamos ênfase nos processos de escolarização. Inclusive são registradas instituições privado-assistenciais que historicamente protagonizaram atendimentos segregados de educação especial ofertando o serviço do AEE às redes públicas de ensino, sendo que as salas de recursos multifuncionais em funcionamento nessas instituições são provenientes dos editais do Programa de Implantação de Salas de Recursos Multifuncionais do governo federal (Brasil, s.d.).

Embora a política de educação especial na perspectiva inclusiva tenha obtido muito apoio no país e buscado estabelecer relações público/privadas para conciliar interesses privados, isso não foi suficiente para apaziguar as resistências internas ao próprio campo, em face das disputas notadas na atuação de organizações privadas que formulam políticas de educação especial desde a sua gênese como política pública no Brasil a partir da criação do CENESP na década de 1970. Ao pensar nas táticas políticas dos setores e grupos que defendem o direito à edu- 
cação escolar, compreendemos que pode ter havido, nos últimos anos, um equívoco ao priorizar a defesa do inclusivo descolado da defesa intransigente da escola pública estatal.

A defesa da educação escolar dos estudantes da educação especial na classe regular não criticou o projeto de educação escolar atual, estabelecido a partir de políticas privatistas, discriminatórias, classificatórias, que vem buscando uma padronização dos desempenhos e o desenvolvimento de competências rebaixadas para o desenvolvimento humano, com base em habilidades necessárias ao mercado. Portanto, a defesa da atuação dos professores de educação especial na escola de ensino regular é fundamental, mas não é suficiente. Assim como não basta os estudantes vinculados à educação especial estarem na escola regular. É preciso disputar o projeto de educação escolar como parte do projeto educacional e societário, a atuação política e pedagógica como diz Florestan, mediante a consciência que essa disputa se realiza no bojo das lutas de classe.

Além das organizações sociais tradicionais, como a Sociedade Pestalozzi e APAEs, que têm capilaridade nacional, outros movimentos vêm ganhando espaço e disputando, mediante a valorização de seus interesses, a direção das políticas de educação especial. Mais recentemente, com a pandemia e o isolamento social, observamos também o crescimento de startups na educação que atendem ao público da educação especial quer seja com tecnologia assistiva ou consultorias às redes de ensino, como mais uma expressão da reforma empresarial da educação que abre caminho para a inovação mercantil no setor ${ }^{1}$.

Os desdobramentos das crises econômicas, em particular a partir de 2008, repercutem ainda mais fortemente na forma de ataques às políticas sociais em favor do acúmulo de capitais, com redistribuição dos recursos do fundo público para o mercado. Nessa conjuntura, a atuação de forças políticas articuladas em torno de uma burguesia conservadora teve como um de seus pontos altos o golpe de Estado que impediu a continuidade do governo de Dilma Rousseff, resultando na articulação de um novo bloco no poder com Michel Temer na presidência da República $^{2}$. Merece destaque no governo Temer, a Emenda Constitucional do teto de gastos, indutora da privatização das áreas sociais e sua transformação em campo de negócios ${ }^{3}$.

Com isso, chegamos à terceira geração de políticas de educação especial, proposta na composição entre os governos Michel Temer (2016 - 2018) e Jair Bolsonaro (2019 - ). Temer dá início ao processo de ajuste que deveria ser realizado nas políticas de educação especial, particularmente, na retomada dos atendimentos segregados para reavivar sua face privatista e estancar os investimentos públicos nas redes públicas de ensino que instituíram novos equipamentos públicos de educação especial, embora numa perspectiva da equidade, gerencial e fracionada. Esse processo de ajuste passa pela contratação de consultorias para reorganização da política, em articulação com a Unesco (Kassar et al., 2019), para colocar em curso uma nova versão das políticas com foco na equidade, ajustando-se à agenda Educação 2030, educação inclusi- 
va, equitativa e ao longo da vida. Portanto, forças políticas já estavam sendo mobilizadas para articular o ajuste demandado pelo capital internacional.

O Banco Mundial (2017) publicou o documento intitulado Um ajuste Justo para o Brasil: análise da eficiência e equidade do gasto público no Brasil, com fortes indicações relativas às questões fiscais, norteando um deslizamento dos investimentos públicos para os capitais internacionais e nacionais. Com esses delineamentos, assim como em outros setores, a proposição política para a educação especial tomou forma no Decreto no 10.502 de 2020, baseada em identificação, classificação, segregação dos sujeitos como processo para a educação. O decreto detalha para a educação especial aquilo que é constitutivo do projeto educacional corrente no Brasil, associado à privatização dos recursos públicos que seriam destinados à área social, o que está nos levando para uma situação tratada por Leher (2020) como darwinismo social.

Tal decreto foi proposto com vistas a desmontar condições já desfavoráveis de desenvolvimento humano para as pessoas com deficiência na relação com a educação escolar, acompanhando outros ajustes realizados no Brasil como a reforma da previdência, a revisão das pensões e dos benefícios de prestação continuada, os contingenciamentos e condicionamentos orçamentários para a educação, a reforma trabalhista e a própria condução dos processos decorrentes da pandemia do Covid-19, apenas para mencionar alguns dos ataques à classe trabalhadora nesse momento. O referido decreto está sustentado em princípios economicamente liberais e politicamente conservadores, defendendo para a educação especial a segregação dos estudantes da educação especial, o que significa historicamente um processo de desescolarização.

Portanto, o ajuste proposto para a educação especial em 2020 é uma expressão do conjunto de ataques à classe trabalhadora que, desde o início do governo Temer e mais ainda com o governo Bolsonaro, vem passando por um aprofundamento. Mas esse não é um movimento apenas nacional; a agenda Educação 2030, difundida pela Unesco (2015), traz consigo um novo ciclo de desescolarização, ainda que mantenha o slogan da educação inclusiva, articulado a aprendizagem ao longo da $v i d a$, o que pressupõe aprendizagens difusas e com dimensões alargadas em relação à vida prática e cotidiana, distanciando-se de um processo de apropriação dos conhecimentos científicos relacionados aos processos de escolarização.

Por sua vez, a Unesco, em 2020, publicou um informe intitulado Inclusão e Educação: todos e todas sem exceção, o qual defende a ideia de inclusão como um processo. Para sustentar essa afirmação apresenta os seguintes dados:

En lo tocante a alumnos con discapacidades, las leyes del $25 \%$ de los países (pero más del $40 \%$ en Asia y en América Latina y el Caribe) definen lugares separados para la enseñanza, el $10 \%$ optan por la integración y el $17 \%$ por la inclusión; en el resto (48\%) se establecen combinaciones de segregación e integración (UNESCO, 2020, p. 9). 
Em face do agravamento da crise do capital, as considerações em relação à educação inclusiva assumem certa naturalização de que países diferentes adotam políticas diferentes de acordo com suas condições num suposto respeito às diferenças dos países. É a meritocracia e a individualização em relação aos países. E isso vem acompanhado pelo discurso cínico de que inclusão é um processo. A constatação de que $48 \%$ dos países articulam combinações de políticas de atendimentos segregados e de integração em relação à educação escolar reforça a perspectiva multifacetada das proposições de inclusão na educação. Tal perspectiva expressa, nas diferenças entre os países, a naturalização das desigualdades.

Os dados apresentados na UNESCO (2020) indicam que a escolarização dos estudantes da educação especial no mundo está longe de se realizar. Ao mesmo tempo em que as proposições contidas em Banco Mundial (2011) e UNESCO (2015) anunciam um novo ciclo de desescolarização proposto pelos organismos internacionais.

\section{Considerações Finais}

Ao longo do presente debate, procuramos discutir a atuação dos organismos internacionais, particularmente Unesco e Banco Mundial, mediante suas orientações às políticas educacionais entre 1990 e 2020. Dedicamo-nos a relacionar elementos pertinentes ao eixo educação e inclusão, retomando as proposições políticas dos anos 1990 e seus desdobramentos e derivações no século XXI.

O período analisado foi constituído por mudanças no mundo do trabalho e no tipo de políticas assumidas pelo Estado burguês em face das necessidades de reprodução do capital em crise. Tais políticas, ao mesmo tempo em que deslizaram os investimentos públicos das áreas sociais para a remuneração de capitais, ajustaram as recomendações educacionais para formar os trabalhadores com habilidades e competências necessárias ao mercado.

Ao analisar os direcionamentos colocados pelos organismos internacionais para o eixo educação e inclusão, identificamos duas estratégias políticas: a ênfase na equidade e na aprendizagem. A equidade é tratada na relação com a educação e a inclusão nos documentos propositivos dos organismos internacionais com a diversificação da oferta educacional, como educação formal, informal, segregada, integrada, inclusiva, regulada, em grande medida, pelos grupos aos quais se destina. Tal estratégia corporifica a flexibilização de currículos, a diferenciação de trajetórias educacionais para diferentes sujeitos. A equidade, embora possa ser apreendida como uma proposta que substitui e atualiza as questões da igualdade, de fato, reforça os mecanismos de desigualdade constitutivos da sociabilidade do capital.

A estratégia da aprendizagem articulada ao eixo educação e inclusão trata do desenvolvimento de habilidades e competências necessárias ao mercado. Os organismos internacionais referem oportunidades de aprendizagem, o que remete para o plano das capacidades individu- 
ais. Ao mesmo tempo, consideram que a aprendizagem prescinde das instituições escolares tal como conhecemos, assim como do conhecimento por elas difundido.

Ao pensar as formas assumidas pelas políticas de educação especial na perspectiva inclusiva no Brasil, reconhecemos, nas suas proposições, os direcionamentos dados pelos organismos internacionais. Analisamos três gerações de políticas de educação especial no Brasil que articulam, de acordo com a conveniência do bloco no poder, tais direcionamentos. Essas diferentes propostas expressam uma perspectiva multifacetada de inclusão nas políticas de educação especial, cuja variabilidade está contemplada nas recomendações dos organismos internacionais. Da mesma forma, as políticas desenvolvidas em diferentes países, que expressam desigualdades naturalizadas, retratam combinações de atendimentos segregados e propostas integracionistas. A perspectiva multifacetada do eixo educação e inclusão nas políticas de educação especial, compreendida aqui como a variabilidade de proposições contempladas na adjetivação inclusiva, potencializa o sentido de coesão e sustentabilidade em relação à sociabilidade do capital. No âmbito das políticas educacionais para os países periféricos, arrola flexibilizações curriculares e individualizações de trajetórias educacionais que, no limite, podem desencadear tanto rebaixamentos formativos como até mesmo processos de desescolarização. Cabe lembrar que tais proposições vêm sendo encaminhadas por meio de propostas focalizadas, direcionadas a grupos identificados como aqueles que expressam diferenças a serem atendidas com ações educacionais específicas.

Tais propostas essecializam os sujeitos nas características que contribuem para que sejam identificados como diferentes e os abstraem das relações de classe social. Se o desafio que temos em relação à educação escolar é imenso, em relação aos sujeitos identificados como estudantes da educação especial não é diferente. Para enfrentá-lo, retomamos Fernandes (2019), para quem atuar na escola implica pensar para além da escola, com forte posicionamento político e com consciência de classe.

Recebido em 15 de maio de 2021 Aprovado em 20 de julho de 2021

\section{Notas}

1 Conforme informações disponíveis no link: <https://insights.liga.ventures/ edtechs/startups-educacao-inclusiva/>.

2 Sobre as implicações do golpe de 2016 sobre as políticas de educação especial ver: Silva; Machado; Silva, 2019.

3 Emenda Constitucional no 95, de 15 de dezembro de 2016, que Altera o Ato das Disposições Constitucionais Transitórias, para instituir o Novo Regime Fiscal, e dá outras providências. 


\section{Referências}

ANTUNES, Ricardo. Os Sentidos do Trabalho: ensaio sobre a afirmação e a negação do trabalho. São Paulo: Boitempo, 2000.

BANCO MUNDIAL. Relatório sobre o desenvolvimento mundial 2000/2001. Luta contra a pobreza. Panorama geral. Washington, 2000.

BANCO MUNDIAL. Social Protection Sector Strategy: from safety net to springboards. S/d. RANSON, S. The new learning for inclusion and capability: towards community governance in the education action zones. OCDE, 2011.

BANCO MUNDIAL. Um Ajuste Justo: análise da eficiência e equidade do gasto público no Brasil. Revisão das despesas públicas. Volume síntese. 2017.

BANCO MUNDIAL. Relatório sobre o Desenvolvimento Mundial. Principais mensagens: Aprendizagem para realizar a promessa da educação. 2018.

BRASIL. Documento orientador programa implantação de salas de recursos multifuncionais. Brasília: MEC, S.d. Disponível em: <http://portal.mec.gov. br/index.php?option=com_docman\&view=download\&alias=11037-doc-orientador-multifuncionais-pdf\&category_slug=junho-2012-pdf\&Itemid=30192>. Acesso em: 02 abr. 2021.

BRASIL. Política Nacional de Educação Especial na Perspectiva da Educação Inclusiva. Brasília: MEC, 2008.

BRASIL. Resolução no 4 de 2009. Diretrizes operacionais para a implantação do atendimento educacional especializado. Brasília: MEC, 2009.

BRASIL. Emenda Constitucional no 95, de 2016. Altera o Ato das Disposições Constitucionais Transitórias, para instituir o Novo Regime Fiscal, e dá outras providências. Diário Oficial da União, Brasília, DF, 16 dez. 2016.

BRASIL. Presidência da República. Decreto no 10.502 de 30 de setembro de 2020. Institui a Política nacional de educação especial: equitativa, inclusiva e com aprendizado ao longo da vida. Diário Oficial da União, 01 out. 2020.

BRESSER PEREIRA, Luiz Carlos. Crise Econômica e Reforma do Estado no Brasil: para uma nova interpretação da América Latina. São Paulo: Editora 34, 1996. CEPAL. Equidad, Desarrollo y Ciudadanía. Vigesimoctavo periodo de sesiones. México, 1990.

CHESNAIS, François. Mundialização: o capital financeiro no comando. Revista Outubro, p. 7-28, 2001.

DAHRENDORF, Ralf (Org.). Report on Wealth Creation and Social Cohesion in a Free Society. London, 1995.

EVANGELISTA, Olinda; SHIROMA, Eneida Oto. O Combate à Pobreza nas Políticas Educativas do Século XXI. In: VIII CONGRESSO LUSO-AFRO-BRASILEIRO DE CIÊNCIAS SOCIAIS, 8., 2004, Coimbra, Portugal. Anais... Coimbra, 2004.

FERNANDES, Florestan. Sociedade de Classes e Subdesenvolvimento. 5. ed. São Paulo: Global, 2008.

FERNANDES, Florestan. A Formação Política e o Trabalho do Professor. Marília, SP: Lutas Anticapital, 2019.

FONTES, Virgini. Capitalismo, Exclusões e Inclusão Forçada. Tempo, Rio de Janeiro, v. 2, n. 3, p. 34-58, 1996.

FREITAS, Luiz Carlos de. Os Reformadores Empresariais da Educação e a Disputa pelo Controle do Processo Pedagógico na Escola. Educação e Sociedade, Campinas, v. 35, n. 129, p. 1085-1114, out./dez., 2014. 
Educação e Inclusão

FREITAS, Luiz Carlos de. Os Novos Reformadores: do discurso da equidade à prática da segregação. Trabalho encomendado GT 15 (Educação Especial) da ANPED. In: REUNIÃO ANUAL DA ANPED, 38., 2017, São Luís, Maranhão. Anais... São Luís, 2017.

FRIGOTTO, Gaudêncio. Exclusão e/ou Desigualdade Social? questões teóricas e político- práticas. Cadernos de Educação, Pelotas, v. 37, p. 417-442, set./dez. 2010.

HABERMAS, Jurgen. Inclusão: integrar ou incorporar? Sobre a relação entre Nação, Estado de direito e Democracia. Novos Estudos CEBRAP, São Paulo, n. 52, p. 99-120, nov. 1998.

HOLZMANN, Robert; JORGENSEN, Steen. Manejo Social del Riesgo: un nuevo marco conceptual para la protección social y más allá. Documento de trabajo n. 0006 sobre protección social. Washington D. C.: Banco Mundial, 2000.

KASSAR, Mônica Carvalho Magalhães; REBELO, Andressa Santos; OLIVEIRA, Regina Tereza Cestari de. Embates e Disputas na Política Nacional de Educação Especial Brasileira. Educação e Pesquisa, São Paulo, v. 45, 2019.

LEHER, Roberto. Um Novo Senhor da educação? A política educacional do Banco Mundial para a periferia do capitalismo. Revista Outubro, p. 19-30, 1999.

LEHER, Roberto. Darwinismo Social, Epidemia e Fim da Quarentena: notas sobre os dilemas imediatos. Carta Maior, 2020. Disponível em: <https://www. cartamaior.com.br/?/Editoria/Politica/Darwinismo-social-epidemia-e-fimda-quarentena-notas-sobre-os-dilemas-imediatos/4/46972>. Acesso em: 02 abr. 2021.

MARX, Karl. As Lutas de Classes na França. São Paulo: Boitempo, 2012.

MELLO, Guiomar Namo de. Cidadania e Competitividade: desafios educacionais do terceiro milênio. São Paulo: Cortez, 1994.

OLIVEIRA, Avelino da Rosa. Exclusão Social - o que ela explica? In: VALLE, Lilian do (Org.). O Mesmo e o Outro da Cidadania. Rio de Janeiro: DP\&A, 2000. P. 87-112.

PARSONS, Talcott. O Sistema Social. Madrid: Alianza Editorial, 1966.

PHILLIPS, David; BERMAN, Yitzhak. Social Quality and Community Citizenship. European Journal of Social Work, Oxford University Press, v. 4, n. 1, p. 17-28, 2001.

POPKEWETZ, Tom; LINDBLAD, Sverker. Estatísticas Educacionais Como um Sistema de Razão: relações entre governo da educação e inclusão/exclusão sociais. Educação e Sociedade, Campinas, v. 22, n. 75, p. 111-148, ago. 2001.

PRONKO, Marcela. O Banco Mundial no Campo Internacional da Educação. In: PEREIRA, João Márcio Mendes (Org.). A Demolição de Direitos: um exame das políticas do Banco Mundial para a educação e a saúde (1980-2013). Rio de Janeiro: Escola Politécnica de Saúde Joaquim Venâncio, 2014. P. 89-112.

ROBERTSON, Susan; VERGER, Antoni. A Origem das Parcerias Público-Privada na Governança Global da Educação. Educação e Sociedade, Campinas, v. 33, n. 121, p. 1133-1156, out./dez. 2012.

SHIROMA, Eneida Oto. A Outra Face da Inclusão. TEIAS: Rio de Janeiro, ano 2, n. 3, jan./jun. 2001.

SILVA, Régis Henrique dos Reis; MACHADO, Robson; SILVA, Ribamar Nogueira da. Golpe de 2016 e a Educação no Brasil: implicações nas políticas de educação especial na perspectiva da educação inclusiva. Revista HISTEDBR online, Campinas, v. 19, 2019. 
UNESCO. Declaração de Salamanca. Salamanca, 1994.

UNESCO. Salamanca - cinco años después. Una revisión de las actividades de UNESCO a la luz de La Declaración y el marco de acción de Salamanca. 1999a.

UNESCO. La participación en la educación para todos: la inclusión de alumnos con discapacidad. Boletín EFA 2000. 1999b.

UNESCO. Educação para Todos: o compromisso de Dakar. In: FÓRUM MUNDIAL DE EDUCAÇÃO, 2000, Dakar. Documento... Dakar, Senegal, 2000.

UNESCO. Declaração de Incheon e Marco de Ação para a Implementação do Objetivo do Desenvolvimento Sustentável 4. Paris, 2015.

UNESCO. Manual para Garantir Inclusão e Equidade na Educação. Brasília, 2019.

UNESCO. Inclusión y Educación: todos y todas sin excepción. Resumen del informe del seguimiento de la educación en el mundo. Paris, 2020.

Rosalba Maria Cardoso Garcia possui doutorado em Educação pela Universidade Federal de Santa Catarina (2004). É professora associada do Departamento de Estudos Especializados em Educação e do Programa de Pós-Graduação em Educação da Universidade Federal de Santa Catarina. Coordenadora do Grupo de Estudo sobre Politica Educacional e Trabalho GEPETO. Membro do Grupo de Pesquisa em Educação Especial.

ORCID: https://orcid.org/0000-0003-3260-6982

E-mail: rosacampeche@uol.com.br

Maria Helena Michels possui doutorado em Educação: História, Política, Sociedade pela Pontifícia Universidade Católica de São Paulo (2004). Em 2018, realizou sua pesquisa de pós-doutorado na Universidade de Playa Ancha (Chile). É professora associada da Universidade Federal de Santa Catarina, vinculada ao Departamento de Estudos Especializados em Educação desde 2006. Membro do Grupo de Estudo sobre Política Educacional e Trabalho e coordenadora do Grupo de Pesquisa em Educação Especial.

ORCID: https://orcid.org/0000-0001-9446-7207

E-mail:mhmichels@uol.com.br

Editora-responsável: Carla Vasques

Este é um artigo de acesso aberto distribuído sob os termos de uma Licença Creative Commons Atribuição 4.0 Internacional. Disponível em: <http:// creativecommons.org/licenses/by/4.0>. 